\title{
Mode of operation of the YiXun e-commerce
}

\author{
Zhang Weiwei \\ Nanchang Key Laboratory of material and structure detection Jiangxi University of Technology
}

Keywords: E-commerce; modes of operation; Yi Xun network; logistics quality

\begin{abstract}
In today's rapid development of Internet Business, people's awareness of e-commerce is more profound than that in the past, and there have been some representative e-commerce enterprises in China, who are influencing the transformation of other companies; an industry's rapid development is often caused by the industry giants, and the development of technology and logistics, as well as the rise of e-commerce talents have broken through the bottleneck of the e-commerce development in the previous. Also, some of China's big e-commerce platforms have changed the Chinese business and trade environment, and the rise of the Internet-related industry has led to the development of e-commerce.
\end{abstract}

\section{Introduction}

As an important part of China's B2C online store, Yi Xun plays a very important role in the development pace and the prospects of B2C in China. Its market share of B2C e-commerce in the country, in recent years, has gradually increased. Faced with the impact from Tmall, Jingdong, Suning and other B2C giants, how Yi Xun would win over more B2C share in the highly competitive market is the problem that we need to solve. Therefore, we will study some advantages, disadvantages, prospects and other aspects of Yi Xun so as to analyze its mode of operation.

\section{Operation Mode Analysis of Yi Xun E-commerce}

On-line operation mode. Positioning:

Yi Xun is the third largest of China's B2C market 3C online shopping platform, where electronic products, household appliances have been the main sales subjects. The benefit of these products lies in the higher single customer price and large margin, but the repeat purchase rate is low, adding to that its single category is not conducive customers one-stop shopping. Hence, Yi Xun has positioned itself in "large and complete", focusing on $3 \mathrm{C}$ and home appliances, and strongly expanding to daily necessities and books: one of Yi Xun's target groups are those who have relatively stable income, who value both the price and the quality of the commodity. Yi Xun has users with higher quality, a wide range of products, hence it should at the same time expand its market share and business scope, so as to accumulate the amount of users, especially those high-quality users.

Online marketing:

Yi Xun now has its own user communication platform: Yi Xun Community. The community has opened up an order-showing thread, discussions thread, quiz thread, the circle thread and other posts sectors. The word of mouth marketing can make users more fixed, and attract new customers, increase their confidence in shopping and brand trust, but also be conducive for Yi Xun staff to 
grasping the first hand data in order to understand customer psychology, improve the problem timely, and increase the transparency of online transactions.

\section{Promotion:}

It can be said that Yi Xun never miss any opportunity to engage in promotional activities. One can find its homepage is full of "discounts", "flash sales", "louder than actions" advertisements. For books anniversary, one can get a deduct of 50 from 200; Yi Xun phone festivals; Yi Xun first television festivals when potential shoppers could win the goods by replies in the post; flash sales in dark and stormy night... People are overwhelmed by all those activities. The most common promotional activities of Yi Xun are: shopping coupon redemption, discounts, auctions; the category also covers such a wide range that fully attracts the attention of various groups of shoppers. The advantage of coupon redemption lies in encouraging customers to buy more products unwittingly by using coupons in limited category at the same time, increasing sales, attracting customers to form a consumption habit and, developing customers loyalty.

Connection to the mobile applications:

Currently, mobile shopping is growing rapidly and has become a new growth point of e-commerce. Yi Xun has seized this new market by covering its mobile application to almost all smart phones and functional mobile phone users, which makes Yi Xun become a leader of the main competitors. Yi Xun has laid a sound technical basis in the mobile Internet era to develop its mobile electronic business. Its mobile application is same with its website, with the functions of commodity browsing, shopping, order tracking, commodity showing, evaluation, and so on, which are quite convenient for mobile phone users.

Off-line operation mode. Off-line advertising and marketing:

(1) sports marketing, sponsorship Chinese Football Association League. In the march of 2012, Yi Xun in a high-profile way, became the main sponsor of Chinese Football Association League. One can say, this marketing tool is helpful to expand the visibility and attention of Yi Xun.

(2) entertainment marketing, television placement, inviting entertainment stars to do endorsements, and running TV ads. For its first attempt, Yi Xun ran on the soft advertising into urban emotional drama "New era of love"; meanwhile, it also hired the drama's actor to be its spokesperson. Since most of audience are white-collar workers and students, overlapping with Yi Xun's major consumer groups, it has effectively established a fashion brand, and also pushed Yi Xun's brand owners to increase sales, and also attracted more quality apparel brand to join.

Featured in a low price and fast delivery to establish brand image:

Yi Xun has seized the success factor of retail industry-- low price, and supported it by with the entire marketing systems and operational systems. The low price, speed logistics have attracted customers, strengthened brand awareness as well as customer loyalty. The biggest advantage of online shopping is its price; compared to the traditional retail business, it has saved the links in rent, wholesale, distributor, and reflected those cost-saving factors on the commercial prices, hence it has great competitiveness and attractiveness. Yi Xun has brought those advantages to the full play.

Public relations:

For the online shopping platform, with the advantage of low prices, it is very crucial to improve profitability by getting a lower purchase price. As for Yi Xun's approach, it has attracted the cooperation from product suppliers with sales volume and the amount of customers. At the same time, Yi Xun has a database docking with Shenzhou database: if there is no goods that customers 
needs in Yi Xun, the system will directly access to the Shenzhou inventory database to reserve this product, has greatly speeding up inventory turnover.

Marketing campaigns:

In the Yi Xun target consumer groups, students play an important role. Because of the convenience and price advantage, many students tend to online shopping. The combination of incentives makes the game not only entertaining but also public beneficial, beautifying Yin Xun brand. This kind of precision marketing imperceptibly conveyed the spirit of the brand and brand message to the target groups, which has both attracted college students for shopping, but also increased social exposure for propaganda purposes.

\section{Improvement strategies and suggestions of Yi Xun e-commerce website operation}

Enlarge gross profit. By the foregoing analysis, we have understood the plight of low-margin has been caught in a vicious circle: in order to be able to make up the shortcomings of various business, the capital investment is required. Because of the limited cash flow, Yi Xun needs to increase sales volume so as to have a larger backlog of money. Greater sales require more and better supporting construction.

Upgrading the channel upgrade, and optimizing the supply:

If Yi Xun wants to support low-margin sales, it is key to optimize the purchase cost, whereas the most crucial step of the optimization is to get onto the upstream of the purchase channels. The delivery volume is a factor on the one hand; on the other hand, it lies in the destructive power of B2C mall on the price system, as well as the information extraction and analysis capability of customers consumption.

Expanding the scale and playing cost advantages:

Apart from the supply optimization, saving the service and operational cost is also effective. The scale advantages could effectively save logistics and other additional costs. Logistics center of Yi Xun "Chinese giant warehouse" has a daily processing capacity up to fifty thousand orders, though the warehouse is still under construction, now its daily processing capacity has already exceeded the daily total orders of Yi nationwide.

Maintenance of Yi Xun credibility. To maintain the credibility mechanism of Yi Xun, it can be divided into two parts: one is public opinion guidance and establishment; the other is public relations crisis.

Daily public opinion guidance and sorting:

It can often be seen in the major forums the complaints about Yi Xun, which has caused bad influence on Yi Xun's credibility. For a long time, Yi Xun customer service has been limited to passively receiving complaints and opinions, hence it is necessary to set up a special active service team to keep an eye on Yi Xun criticism and complaints appeared in the mainstream media and forum. This will not only solve the customer's sales issues, but also reflects a sense of responsibility of Yi Xun, and creates a good reputation.

The degree of being concerned:

Mass incidents are easy to occur because of Yi Xun's errors in the work. But now, there is no specialist to conduct public relations work for unexpected events. The way how Yi Xun deals with current crisis also reveals its slight immaturity, and often has been questioned by various parties. It is necessary to set up a special crisis public relations department, on the one hand to develop plans for 
emergencies; the other hand, through the network hype, to increase the degree of public attention on Yi Xun.

Using self logistics to improve logistics quality. To set up self logistics plan is an important measure to enhance the quality of logistics for Yi Xun. The biggest difference from outsourcing logistics is that: self logistics can enhance the professionalism and controllablity of the sale of goods. Upgrading of the profession of logistics means, B2C companies can improve the packaging and distribution process for the sale of goods. Fragile goods, precious commodities, flammable liquids can be treated differently; more unified goods packing, more reasonable placement of transport and protection. And one could get transport characteristics of goods by simply scanning two-dimensional code.

Services improving and the soft power branding. If one calls 400 customer service hot-line, it is far from satisfactory. Yi Xun customer service capabilities have failed to catch up with the fast-growing sales of Yi Xun itself. The emergence of this issue, partly because of insufficient capital investment, and lack of experience, partly because of the not yet formed effective management system. For a long time, Yi Xun as well as its suppliers have regarded after-sales service as the burden, passing the buck to each other. Eventually it has led to a substantial decline in consumer brand awareness of the Yi Xun. For example, the defective products sold by Yi Xun requires customers to conduct a testing in designated site, and issue a test report to prove commodity is "bad out of the box ". Only by this means will Yi Xun be responsible for goods returns.

\section{Conclusion}

B2C online shopping as a new consumption pattern, is becoming more and more acceptable by consumers, both because of price advantage, in fact, but also because of pursuit to a new lifestyle. When the customer makes decision to buy product online, he would consider on price, shopping environment, quality of service, shopping experience, product quality and other factors .

Yi Xun continues to impress people with the low price. In the short term, it indeed attracts more customer; however, how to retain customers with good quality service and form a brand effect is the key to ensure the long-term development. Yi Xun, though has some efforts in this regard: its self logistics, integrated platform, campaigns and others marketing strategies are all out of above consideration, and also have achieved a certain effect. The author is afraid to say, there is still a long way for Yi Xun to go, in how to find a balance between the rapid development of business and services and technology management, how to cultivate its brand among consumers and maintain its image, how to get greater profi by fast-growing sales.

\section{Acknowledgment}

This work was supported by Project on professional and characteristical construction of Jiangxi province 2010 (Civil Engineering) and Project on the planning and construction of disciplines in Jiangxi University of Technology (Structure Engineering)

\section{References}

[1] Dong Shaobin. SME e-business model and route choice . [J]. Enterprise Economy 2011

[2] Li Li.E-commerce operation and organization model analysis. [J]. Chinese Trade. 2011 
[3] Zhao Qiao. Online innovation marketing model under e-commerce environment[J]. Chinese Trade. 2011

[4] Wang Qing. Study on B2C e-commerce business model [J]. Science and Technology Innovation Herald 2011

[5] Lai Wenwen .B2C e-business development strategy and service model study [J]. Science and Technology Innovation Guidance 2011

[6] Li Jiyue. Logistics problem of B2C e-commerce in China -- taking Jingdong Mall as an example [J] Logistics Technology 2011.

[7] Wen Xuli, Tian Ruiqing. Research on B2C e-business logistics mode -- A Case Study of VANCL [J] Logistics Technology 2011.

[8] Bu Guangqi. Successful marketing, V Marketing China, The Editorial Department Mailbox, 2013 03

[9]He Zhengyou Qian Qingquan Wang Zhibing Institute of Electrification and Automation,Southwest Jiaotong University Cheng Du,610031,China

[10]Anna Gutowska,Andrew Sloane,and Kevan A.Buckley School of Computing and Information Technology,University of Wolverhampton,Wolverhampton,WV1 1SB,U.K.

[11]Zhu Zijun.China’s Foreign Trade .2012

[12]Kuang Yan.Science \& Technology Information.2012 